\title{
Seleção de leveduras da Região Amazônica para produção de protease extracelular
}

\author{
Kilma Cristiane SILVA NEVES ${ }^{1}$; Ana Lúcia Figueiredo PORTO ${ }^{2,3}$; Maria Francisca Simas TEIXEIRA ${ }^{4}$
}

\section{RESUMO}

O objetivo deste trabalho foi identificar 50 leveduras isoladas a partir de diferentes substratos da Região Amazônica e selecionar uma espécie de maior atividade proteolítica. Entre as 26 espécies identificadas predominaram Candida aquatica (12\%) e Candida tropicalis (10\%). A fermentação submersa foi realizada em Extrato de Malte suplementado com gelatina 1\%, Candida intermedia foi a que expressou maior atividade proteolítica, halo $=25 \mathrm{~mm}$ e $273 \mathrm{U} / \mathrm{mL}$, crescimento máximo a $30^{\circ} \mathrm{C}$, viabilidade celular $6,2 \times 10^{6}$ UFC, em 48 horas, não demonstrou características de patogenicidade e a melhor densidade do inóculo foi 3\%, utilizando-se culturas com 24 horas de crescimento em ágar Malte.

\section{PALAVRAS-CHAVES}

Leveduras, Região Amazônica, Protease

\section{Screening of yeasts from Amazon Region for extracellular protease production}

\section{ABSTRACT}

The objective of this work was to identify 50 yeasts isolates obtained from differents substracts from Amazon Region and to select one species of higher proteolytic activity. Among the 26 identified species it had predominance of Candida aquatica (12\%) and Candida tropicalis (10\%). The submerged fermentation was carried out in Malt Extract supplemented with gelatin 1\%, Candida intermedia exhibited higher proteolytic activity, halo $=25 \mathrm{~mm}$ and $273 \mathrm{U} / \mathrm{mL}$, the maximum growth $30^{\circ} \mathrm{C}$, the cellular viability $6.2 \times 10^{6} \mathrm{UFC}$, in 48 hours, did not demonstrate pathogenicity characteristics and the best inoculum density tested was 3\%, using 24 hours Malt agar cultures.

\section{KEY-WORDS}

Yeasts, Amazon Region, Protease

\footnotetext{
${ }^{1}$ Departamento de Parasitologia-Laboratório de Micologia/UFAM-Av. Gen. Otávio Jordão Ramos, n. 3000, Coroado I, Minicampus Universitário-Aleixo. CEP 69077-000. E-mail: kicri@uol.com.br ${ }^{2}$ Departamento de Morfologia e Fisiologia Animal/ UFRPE - Rua D. Manoel de Medeiros s/n, Dois Irmãos. CEP: 52171-300. E-mail: anaporto@ufrpe.br ${ }^{3}$ Laboratório de Imunopatologia Keizo Asami- Lika/ UFPE - Av. Moraes Rego s/n, Cidade Universitária. CEP: 50670-901 E-mail: anaporto@lika.ufpe.br

${ }^{4}$ Departamento de Parasitologia - Laboratório de Micologia/ UFAM - Av. Gen. Otávio Jordão Ramos, n. 3000, Coroado I, Minicampus Universitário - Aleixo. CEP 69077-000. E-mail: mteixeira@ufam.edu.br
} 


\section{INTRODUÇÃO}

Proteases são utilizadas em diversas atividades industriais tais como processamento de alimentos, bebidas, formulação de detergentes, processamento de couro e pele, no amaciamento de carne e formulação de medicamentos etc. O uso dessas enzimas corresponde a $40 \%$ do mercado mundial de biocatalisadores, avaliado em 1 bilhão de dólares (Soares et al., 1999).

São fontes de proteases, os vegetais, animais e microrganismos (fungos e bactérias). Entre os microrganismos produtores de enzimas as leveduras têm destaque como fonte de biocompostos, entre os quais predominam as proteínas. São microrganismos bastante usados na indústria de alimentos porque a maioria das espécies não apresenta características patogênicas (Rodrigues \& Sant'anna, 2001).

$\mathrm{Na}$ natureza grande parte da atividade necessária para o aproveitamento da matéria orgânica é realizada por fungos e bactérias produtores de enzimas. Tais microrganismos representam excelente fonte de enzimas devido à facilidade de manipulação genética e a ampla diversidade bioquímica. Nesse contexto, as proteases de origem microbiana são preferidas em relação às de origem animal e vegetal por expressarem características desejadas para aplicação biotecnológica (Godfrey \& West, 1996).

As leveduras têm distribuição mundial e metabolismo diversificado, especialidade fisiológica que proporciona a utilização de uma variedade de nutrientes em distintas condições ambientais (Kirsop \& Kurtzman, 1988; Tornai-Lehoczki et al., 2003).

As leveduras são muito versáteis e muitas delas são peculiarmente apropriadas para propósitos industriais. Identificar leveduras de forma rápida e confiável pode ser importante na indústria, para estabelecer precisamente as causas de contaminação indesejada, e na medicina, para o diagnóstico de certas doenças. Uma identificação rápida em certos contextos também pode ser crucial, como por exemplo, quando uma determinada levedura está sendo utilizada industrialmente ou em experimentos de laboratório (Barnett, 1990).

Devido o grande potencial microbiológico da Região Amazônica e a crescente aplicabilidade de enzimas na área biotecnológica, torna-se viável selecionar e identificar microrganismos produtores do complexo proteolítico. O objetivo deste trabalho foi investigar a potencialidade de leveduras isoladas de diferentes substratos da Região Amazônica na produção de proteases para aplicação na indústria.

\section{MATERIAL E MÉTODOS}

Foram analisadas 50 amostras de leveduras da Região Amazônica pertencentes aos gêneros Saccharomyces, Rhodotorula, Trichosporon, Candida, Cryptococcus, Lipomyces, Dekkera, Pichia, Sporobolomyces e Hansenula, do acervo da micoteca do
Departamento de Parasitologia da Universidade do Amazonas. Após reativação das culturas preservadas em água destilada esterilizada, as leveduras foram identificadas, em nível de espécie, com base nas características morfológicas, de reprodução e fisiológicas (Barnett et al., 1990; Fisher \& Cook, 1998, Kreger Van Rij, 1984; Lodder, 1984). Utilizou-se também o sistema de identificação comercial API 20C AUX (bioMérieux).

Para selecionar uma espécie produtora de alta atividade proteolítica, as leveduras foram cultivadas em ágar Malte, a 30 ${ }^{\circ} \mathrm{C}$ por 72 horas para obtenção de cultura-estoque. Todos os experimentos foram realizados em triplicata. Os dados foram submetidos à estatística descritiva de acordo com Callegari-Jacques (2003), utilizou-se o programa Microsoft/Excel, 2000 e os resultados expressos em média.

A partir da cultura-estoque foi preparada suspensão padronizada pela escala de MacFarland 3. De cada suspensão foi retirado $1000 \mathrm{~mL}$ para inoculação em Erlenmeyers de $50 \mathrm{~mL}$ contendo $10 \mathrm{~mL}$ de Extrato de Malte com gelatina 1\% (p/v). A fermentação submersa foi mantida a $30^{\circ} \mathrm{C}$, sob agitação $(140$ rpm) e após 72 horas a biomassa foi separada do extrato enzimático por centrifugação (12.000 g/ 5 min.) (Barnett et al., 1990; Becker et al., 1996; Porto et al., 1996). A atividade enzimática foi determinada pelo método de cup-plate, em ágar gelatina-leite, de acordo com a metodologia descrita por Teixeira et al. (1996).

No sobrenadante foi determinada a atividade proteolítica a $37^{\circ} \mathrm{C}$ utilizando-se como substrato azocaseína 1,0\% (p/v) (Sigma, St. Louis, MO USA), em tampão 0,2 M Tris-HCl, $\mathrm{pH} 7,2$, contendo 1,0 $\mathrm{mM} \mathrm{de} \mathrm{CaCl}_{2}$ (Dosoretz et al., 1990; Leighton et al., 1973; Porto et al., 1996). Uma unidade de atividade proteolítica foi definida como a quantidade de enzima capaz de produzir um aumento na absorvância de $0,001 / \mathrm{min}$. em uma hora a $440 \mathrm{~nm}$, sendo expressa em $\mathrm{U} / \mathrm{mL}$.

Para manutenção de cultura pura e produção de células viáveis da espécie proteolítica selecionada, fragmentos de cultura monospórica foram transferidos para ágar Sabouraud e ágar Malte. Os cultivos em tubo de ensaio foram mantidos a $30^{\circ} \mathrm{C}$ durante 24 horas para realização dos experimentos descritos a seguir.

Para identificação dos fatores de patogenicidade foram consideradas as seguintes características: atividade fosfolipásica, ureásica e o crescimento a $37^{\circ} \mathrm{C}$ (Nunes, 1998; Price et al., 1982), e a viabilidade celular foi determinada por meio da técnica de semeadura em profundidade em ágar Malte. As placas foram incubadas a $30^{\circ} \mathrm{C}$ por 72 horas. As colônias foram contadas e os resultados expressos em unidades formadoras de colônia (UFC) (Brock et al., 1994).

A produção de protease pela espécie selecionada foi realizada por fermentação submersa. Determinou-se o tamanho e a idade do inóculo preparando-se uma suspensão celular nas culturasestoque obtidas em ágar Malte, ágar Sabouraud e ágar com sais minerais, inclinado, a $30^{\circ} \mathrm{C}$, durante 24 e 72 horas. Todas as 
suspensões foram padronizadas pela Escala de MacFarland 3.

De cada suspensão foi retirada uma alíquota correspondente às seguintes concentrações: 3\%, 5\%, 8\% e 10\% (v/v) para ser adicionada em Erlenmeyer de $50 \mathrm{~mL}$ contendo $10 \mathrm{~mL}$ de Caldo de Sabouraud, Extrato de Malte e solução de sais, todos suplementados com gelatina 1\% (García-Garibay et al., 1987; Nampoothiri \& Pandey, 1995; Stanbury \& Whitaker, 1994).

Os cultivos foram mantidos a $30^{\circ} \mathrm{C}$ sob agitação (140 rpm). Após 24 horas esses cultivos foram transferidos para Erlenmeyers de $125 \mathrm{~mL}$, obtendo-se um volume final de $40 \mathrm{~mL}$ dos meios utilizados experimentalmente. A fermentação foi mantida a 30 ${ }^{\circ} \mathrm{C}$, a $140 \mathrm{rpm}$ por 72 horas. Ao término do processo de fermentação a biomassa foi separada do extrato enzimático por centrifugação e a atividade enzimática foi determinada de acordo com a metodologia recomendada por Porto et al. (1996).

$\mathrm{Na}$ determinação da temperatura ótima de crescimento e produção de protease a $25^{\circ} \mathrm{C}, 30^{\circ} \mathrm{C}, 40^{\circ} \mathrm{C}$ e $50^{\circ} \mathrm{C}$ utilizouse o inóculo padronizado em Erlenmeyers de $50 \mathrm{~mL}$ contendo $10 \mathrm{~mL}$ do meio. Os cultivos foram mantidos sob agitação (140 $\mathrm{rpm}$ ). Após 24 horas de fermentação os cultivos foram transferidos para Erlenmeyers de $125 \mathrm{~mL}$ de forma a se obter volume final de $40 \mathrm{~mL}$ do meio.

O crescimento da espécie selecionada foi avaliado determinando-se o peso da biomassa desidratada a $80^{\circ} \mathrm{C}$, utilizando-se papel de filtro INLAB tipo 30 . O peso da matéria seca foi determinado a cada 12 horas, durante 72 horas. A atividade enzimática foi determinada a cada 12 horas.

\section{RESULTADOS E DISCUSSÃO}

Os resultados referentes à identificação das 50 amostras de leveduras pertencentes aos gêneros Candida, Cryptococcus,
Dekkera, Hansenula, Lipomyces, Pichia, Rhodotorula, Saccharomyces, Sporobolomyces e Trichosporon demonstraram que essas unidades taxonômicas estavam representadas por 26 espécies (Figura 1). Entre estas, as de maior freqüência foram Candida aquatica (12\%) e Candida tropicalis (10\%).

Entre as leveduras, diversas espécies estão associadas a processos industriais e/ou descritas como patógenas oportunistas. São microrganismos de relevância por serem ótimas produtoras de biocompostos e constituírem fonte de proteínas e vitaminas (Aoki et al., 1994; Kirsop \& Kurtzman, 1888; Macdonald \& Odds, 1980; Shimizu et al., 1987; Yamamoto et al., 1992).

Para utilização de fonte microbiana na produção de compostos ou em processos na indústria de alimentos ou medicamentos exige-se que este não seja patogênico, não produza micotoxinas ou outras substâncias tóxicas (Fungaro et al., 1994). Nas análises realizadas para detecção dos fatores de patogenicidade de Candida intermedia, observou-se o crescimento positivo a $37{ }^{\circ} \mathrm{C}$. No entanto, não se detectou atividade fosfolipásica nem ureásica.

Os dados disponíveis não são suficientes para classificar Candida intermedia como patogênica, visto que um único fator não pode determinar a virulência de qualquer espécie fúngica, mas depende de um conjunto de fatores, a exemplo da capacidade de adesão, produção de fosfolipase, urease, crescimento a $37^{\circ} \mathrm{C}$ e adaptação morfogenética às condiçôes do hospedeiro (MendesGiannini et al., 1997; Midgley et al., 1998).

O microrganismo deve apresentar viabilidade celular para ser efetivo nos processos de fermentação. A viabilidade celular corresponde à capacidade da célula se dividir e formar sucessivas novas células. A maneira usual de se realizar a contagem de células viáveis baseia-se na determinação do número de células na amostra capazes de formar colônias no meio de cultura seletivo. Através

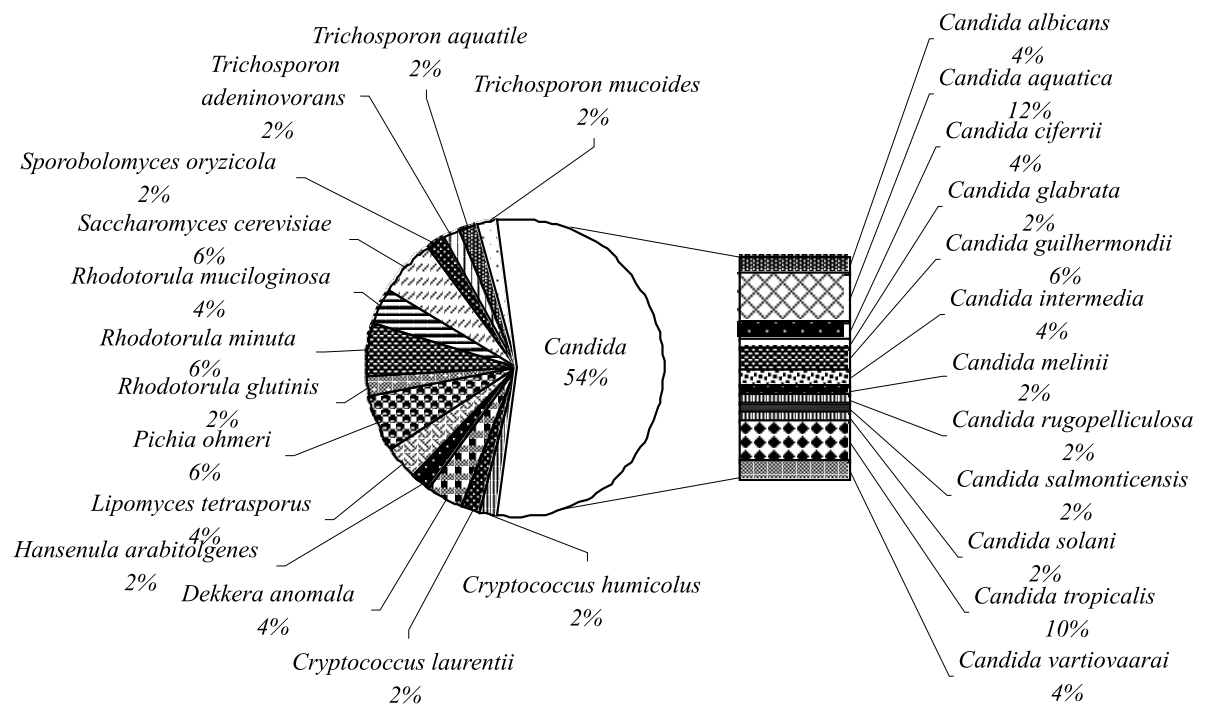

Figura 1 - Freqüência das espécies de leveduras da Região Amazônica selecionadas para produção de protease extracelular. 
Tabela 1 - Produção de protease por diferentes espécies de leveduras, em Extrato de Malte suplementado com gelatina 1\%, a $30{ }^{\circ} \mathrm{C}$, sob agitação (140 rpm), durante 72 horas.

\begin{tabular}{|c|c|c|c|c|c|}
\hline \multirow[b]{2}{*}{ Espécies } & \multicolumn{2}{|c|}{ Atividade proteolítica } & \multirow[b]{2}{*}{ Espécies } & \multicolumn{2}{|c|}{ Atividade proteolítica } \\
\hline & $(\mathrm{mm})$ & $(\mathrm{U} / \mathrm{mL})$ & & $(\mathrm{mm})$ & $(\mathrm{U} / \mathrm{mL})$ \\
\hline Candida albicans & 16 & $31 \pm 0,00$ & Candida vartiovaarai & 12 & $40 \pm 0,19$ \\
\hline Candida albicans & 15 & $71 \pm 0,00$ & Candida vartiovaarai & 12 & $53 \pm 0,38$ \\
\hline Candida aquatica & 13 & $255 \pm 0,58$ & Cryptococcus humicolus & 0 & $0 \pm 0,00$ \\
\hline Candida aquatica & 10 & $184 \pm 0,00$ & Cryptococcus laurentii & 10 & $31 \pm 0,00$ \\
\hline Candida aquatica & 12 & $51 \pm 0,00$ & Dekkera anomala & 10 & $44 \pm 0,00$ \\
\hline Candida aquatica & 12 & $38 \pm 0,19$ & Dekkera anomola & 20 & $60 \pm 0,00$ \\
\hline Candida aquatica & 13 & $47 \pm 0,58$ & Hansenula arabitolgenes & 11 & $22 \pm 0,00$ \\
\hline Candida aquatica & 10 & $40 \pm 0,00$ & Lipomyces tetrasporus & 10 & $27 \pm 0,00$ \\
\hline Candida ciferrii & 20 & $78 \pm 0,00$ & Lypomyces tetrasporus & 18 & $53 \pm 0,38$ \\
\hline Candida ciferrii & 10 & $53 \pm 0,00$ & Pichia ohmeri & 13 & $33 \pm 0,03$ \\
\hline Candida glabrata & 10 & $11 \pm 0,00$ & Pichia ohmeri & 10 & $47 \pm 0,00$ \\
\hline Candida guilhermondii & 10 & $80 \pm 0,00$ & Pichia ohmeri & 13 & $47 \pm 0,00$ \\
\hline Candida guilhermondii & 12 & $47 \pm 0,00$ & Rhodotorula glutinis & 12 & $27 \pm 0,00$ \\
\hline Candida guilhermondii & 10 & $24 \pm 0,00$ & Rhodotorula minuta & 17 & $55 \pm 0,00$ \\
\hline Candida intermedia & 18 & $64 \pm 0,00$ & Rhodotorula minuta & 10 & $29 \pm 0,00$ \\
\hline Candida intermedia & 25 & $273 \pm 0,00$ & Rhodotorula minuta & 15 & $33 \pm 0,00$ \\
\hline Candida melinii & 12 & $78 \pm 0,00$ & Rhodotorula muciloginosa & 11 & $20 \pm 0,38$ \\
\hline Candida rugopelliculosa & 20 & $44 \pm 0,00$ & Rhodotorula muciloginosa & 12 & $27 \pm 0,00$ \\
\hline Candida salmonticensis & 12 & $71 \pm 0,00$ & Saccharomyces cerevisiae & 10 & $80 \pm 0,03$ \\
\hline Candida solani & 19 & $55 \pm 0,37$ & Saccharomyces cerevisiae & 10 & $35 \pm 0,00$ \\
\hline Candida tropicalis & 15 & $18 \pm 0,00$ & Saccharomyces cerevisiae & 10 & $31 \pm 0,19$ \\
\hline Candida tropicalis & 15 & $22 \pm 0,21$ & Sporobolomyces oryzicola & 17 & $51 \pm 0,00$ \\
\hline Candida tropicalis & 23 & $40 \pm 0,00$ & Trichosporon adeninovorans & 16 & $40 \pm 0,00$ \\
\hline Candida tropicalis & 10 & $38 \pm 0,03$ & Trichosporon aquatile & 10 & $140 \pm 0,57$ \\
\hline Candida tropicalis & 12 & $44 \pm 0,00$ & Trichosporon mucoides & 12 & $33 \pm 0,00$ \\
\hline
\end{tabular}

do procedimento de contagem celular presume-se que cada célula viável irá produzir uma colônia (Brock et al., 1994).

Com o objetivo de contar apenas células vivas foi realizado o método de contagem de células viáveis associada à determinação do quantitativo de UFC (Unidades Formadoras de Colônia).

Nos testes realizados para se determinar a viabilidade celular de Candida intermedia, os resultados obtidos confirmaram o crescimento dessa levedura no meio seletivo. Assim sendo, nas condiçôes analisadas observou-se o crescimento da levedura, determinando-se, em média, a contagem de UFC igual a $6,2 \mathrm{x}$ $10^{6} \mathrm{em} 48$ horas.

Para obtenção de ótimos rendimentos, em relação à produção de enzimas, durante o desenvolvimento dos diferentes tipos de cultivos, não só o número de células influencia, mas também o meio usado para fermentação, a temperatura usada para crescimento do microrganismo e a idade do inóculo (Brumano et al., 1993; Papagianni \& Moo-Young, 2001).
A Figura 2 demonstra o desempenho de Candida intermedia quando se utilizou diferentes concentrações de inóculo em fermentação submersa. Os resultados mostraram que as maiores atividades proteolíticas $(333 \mathrm{U} / \mathrm{mL})$ foram determinadas quando se utilizou inóculo equivalente a $3 \%$ do volume de meio e cultura estoque com 24 horas de crescimento no meio sólido (ágar Malte).

Os resultados evidenciaram que o tamanho e a idade do inóculo influenciaram diretamente na secreção de protease, tanto que, o aumento da atividade foi inversamente proporcional ao aumento da concentração do inóculo (Figura 2). Outros parâmetros que influenciam no rendimento enzimático são composição do meio, temperatura, o período de incubação e a capacidade de germinação dos esporos (Freire, 1996; Teixeira, 1997).

Nas diferentes condições de cultivo observou-se que as maiores atividades proteásicas foram obtidas com o inóculo de menor concentração (3\%). Esses resultados comprovam que a produção de enzimas de origem microbiana depende 
principalmente do próprio microrganismo, visto que nos cultivos tipo "sistema fechado" a concentração de nutrientes, biomassa e os metabólitos alteram constantemente, devido ao metabolismo microbiano (Brumano et al., 1993; Teixeira, 1997; Tucker \& Thomas, 1994).

Nos experimentos realizados com o inóculo mais concentrado (10\%) nos meios de cultura testados verificou-se que Candida intermedia apresentou viabilidade diferenciada, ou seja, menor produção de enzima (Figura 2). Provavelmente, este resultado esteja relacionado com o processo de germinação do esporo, $\mathrm{o}$ qual está regulado por estímulos ambientais, pelas propriedades genéticas, fisiológicas e bioquímicas do próprio microrganismo (Griffin, 1994).

Esses resultados corroboram os resultados obtidos por GarciaGaribay et al. (1987), Nampoothiri \& Pandey (1995), Papagiannie \& Moo-Young (2001), nos quais a atividade enzimática foi diretamente influenciada pela concentração e idade do inóculo. Danesi \& Wosiacki (1998), verificaram a influência da quantidade do inóculo utilizando volumes que variaram entre 10 a 25\% e obtiveram melhor resposta utilizando o inóculo de menor concentração.

Com relação aos meios usados, nesse experimento, para fermentação comprovou-se que Extrato de Malte foi mais eficiente em relação à Solução de Sais e Caldo de Sabouraud, $34 \%$ e $47 \%$, respectivamente. Essa afirmativa está associada às atividades proteolíticas máximas $(220 \mathrm{U} / \mathrm{mL}$ e $178 \mathrm{U} / \mathrm{mL})$ determinadas em Solução de Sais e Caldo de Sabouraud, respectivamente (Figura 2).

A temperatura constitui um dos mais importantes fatores que influenciam no crescimento e sobrevivência dos organismos. Usualmente $\mathrm{o}$ alcance de temperatura para um organismo viável está em torno de $30^{\circ} \mathrm{Ce} 40^{\circ} \mathrm{C}$, embora alguns microrganismos apresentem uma tolerância maior que outros (Brock et al., 1994).

Nos experimentos realizados para determinar a temperatura ótima de crescimento, Candida intermedia demonstrou o crescimento máximo $(4,67 \mathrm{mg}$ de biomassa $/ \mathrm{mL})$ a $30^{\circ} \mathrm{C}$, em 36 $\mathrm{h}$ de fermentação (Figura 3). Essa característica fisiológica determina a classificá-lo como mesofílica. Microrganismos mesofílicos são aqueles que crescem entre $10^{\circ} \mathrm{C} \mathrm{a} 45^{\circ} \mathrm{C}$ e tem temperatura ótima de crescimento entre $15^{\circ} \mathrm{Ca} 40{ }^{\circ} \mathrm{C}$ (Brock et al., 1994; Deacon, 1997; Griffin, 1994).

De acordo com a Figura 3, Candida intermedia não apresentou crescimento típico (fases: de adaptação, exponencial, estacionária e declínio) nas diferentes temperaturas. A ausência da fase de adaptação esta diretamente relacionada com a viabilidade das células do inóculo, isto é, não houve necessidade de resíntese de biocompostos para a levedura iniciar o crescimento (Brock et al., 1994).

Nas temperaturas de $25^{\circ} \mathrm{C}, 40^{\circ} \mathrm{Ce} 50^{\circ} \mathrm{C}$ observou-se que C. intermedia expressou as fases exponencial, estacionária e de
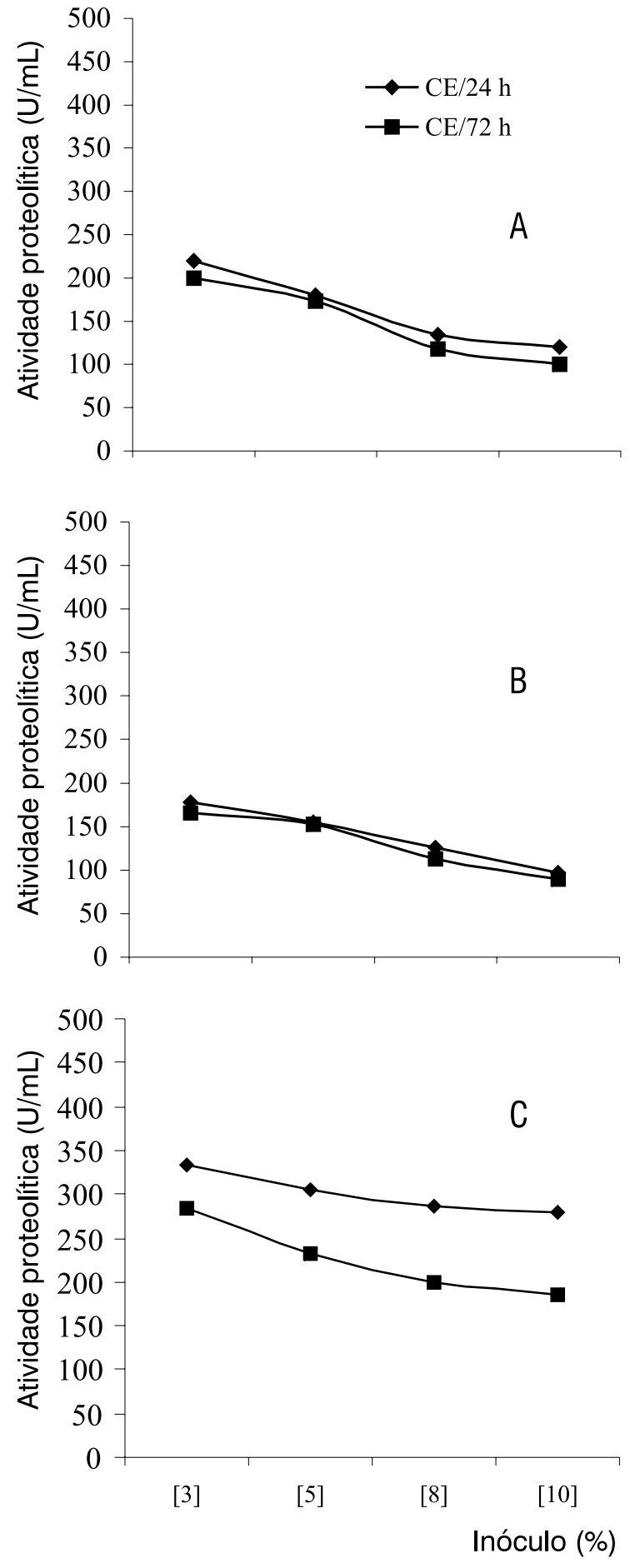

Figura 2 - Influência da concentração do inóculo e da cultura estoque (CE) na produção de proteases por $C$. intermedia, em cultivos obtidos em $40 \mathrm{~mL}$ de (A) Solução de sais; (B) Caldo de Sabouraud e (C) Extrato de Malte, mantidos a $30^{\circ} \mathrm{C}$, sob agitação (140 rpm) por 72 horas. 
declínio, no entanto, a $30^{\circ} \mathrm{C}$ não ocorreu a fase estacionária. Provavelmente essa tendência para o fim do crescimento pode ser atribuída a uma série de circunstâncias, particularmente à exaustão de alguns nutrientes e com menos freqüência à produção de compostos tóxicos (Brock et al., 1994).

Comparando o crescimento de Candida intermedia apresentado na Figura 3, os resultados mostraram também que a $30^{\circ} \mathrm{C}$ foi $7 \%$ superior daquele expressado a $25^{\circ} \mathrm{C}$. Quando se avaliou o crescimento dessa levedura a $40^{\circ} \mathrm{Ce} 50^{\circ} \mathrm{C}$ identificouse que houve redução da biomassa equivalente a $21,84 \%$ e $33,62 \%$, respectivamente.

O crescimento apresentado por Candida intermedia nas diferentes temperaturas está em concordância com as citaçōes de Griffin (1994). Este autor ao discutir o crescimento de Saccharomyces cerevisiae conclui que as leveduras predominam em baixas temperaturas. Determinadas espécies patógenas oportunistas, a exemplo de Candida albicans, são adaptadas ao crescimento a $37^{\circ} \mathrm{C}$.

A temperatura constitui outro parâmetro crítico que influencia na produção de enzima, precisa ser controlado e varia de organismo para organismo (Chaloupka, 1985). Na Figura 4 estão os resultados da produção de proteases em diferentes temperaturas $\left(25^{\circ} \mathrm{C}, 30^{\circ} \mathrm{C}, 40^{\circ} \mathrm{Ce} 50^{\circ} \mathrm{C}\right)$. Observou-se que as atividades proteolíticas foram detectadas desde o início do processo de fermentação em todos os ensaios.

A máxima atividade proteolítica $(356 \mathrm{U} / \mathrm{mL})$, nas diferentes temperaturas, foi determinada no extrato bruto $C$. intermedia a $30^{\circ} \mathrm{C}$ (Figura 4). Estes resultados estão de acordo com as citaçōes de Chantawannakul et al. (2002), Kanekar et al. (2002), Petinate et al. (1999), Yang \& Lin (1998) e Yang et al. (1999).

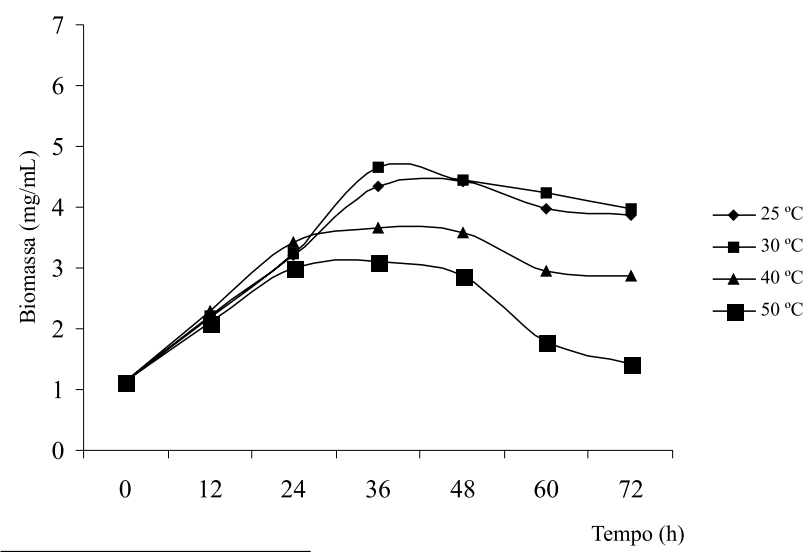

Figura 3 - Temperatura ótima de crescimento relacionada ao peso seco da biomassa produzida por Candida intermedia, em Extrato de Malte, suplementado com gelatina $1 \%$, mantidos sob agitação (140 rpm), durante 72 horas.
Verificou-se ainda que os menores níveis de protease nas culturas de Candida intermedia ocorreram a $50^{\circ} \mathrm{C}$ demonstrando atividade máxima de $233 \mathrm{U} / \mathrm{mL}$, em 48 horas de fermentação. Este quantitativo proteolítico corresponde a um decréscimo de $34,5 \%$ quando comparado ao nível máximo da produção da enzima a $30^{\circ} \mathrm{C}$.

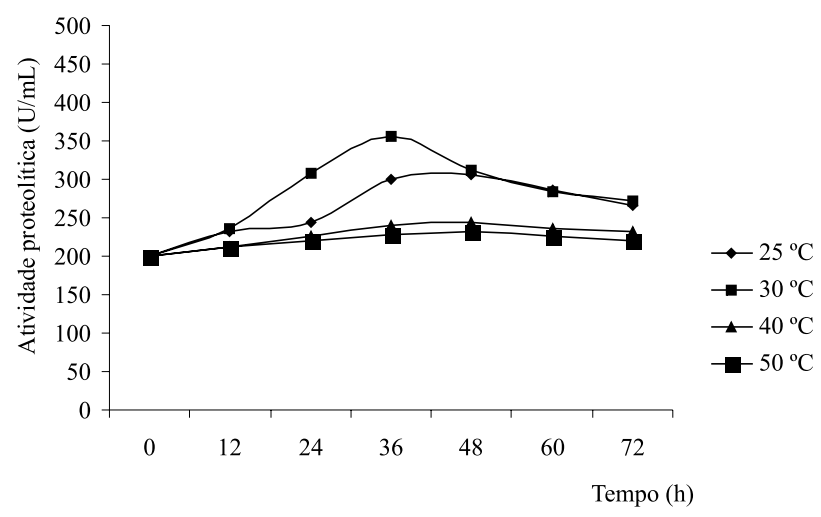

Figura 4 - Temperatura ótima de crescimento relacionada à produção de protease por Candida intermedia, em Extrato de Malte, suplementado com gelatina $1 \%$, mantidos sob agitação (140 rpm), durante 72 horas.

\section{CONCLUSÕES}

Entre as leveduras isoladas na Região Amazônica, as espécies mais freqüentes foram Candida aquatica e Candida tropicalis. Nas análises quantitativas e qualitativas a maioria das leveduras produziu protease, entre estas Candida intermedia foi a espécie que expressou maior atividade proteolítica.

C. intermedia não apresentou características de patogenicidade e as condições de fermentação que proporcionaram maior produção de protease foram: temperatura de $30^{\circ} \mathrm{C}$ e inóculo equivalente a $3 \%$ do volume do meio (Extrato de Malte e gelatina $1 \%$ ) utilizando cultura estoque com 24 horas de crescimento em ágar Malte.

\section{BIBLIOGRAFIA CITADA}

Ammerer, G.; Hunter, C. P.; Rothman, J. H.; Saari, G. C.; Valls, L. A.; Stevens, T. M.1986. PEP4 gene of Saccharomyces cerevisiae encodes proteinase $\mathrm{A}$, a vacuolar enzyme required for processing of vacuolar precursors. Mol. Cell. Biol., (6): 2490- 2497.

Aoki, S.; Ito-kuwa, S.; Nakamura, K., Kato, J.; Ninomiya, K.; Vidotto, V. 1994. Extracellular proteolytic activity of Cryptococcus neoformans. Mycopathologia , (128): 143- 150.

Barnett, J. A.; Payne, R. W.; Yarrow, D. 1990. Yeast Characteristics and Identification. $2^{\text {nd }}$ ed. Cambrige: University Press, Cambrige. 1200 pp.

Becker, J. M.; Caldwell, G. A.; Zachgo, E. A. 1996. Biotechnology: a laboratory course. $2^{\text {nd }}$ ed. Academic Press, London. 261pp.

Braga, A. A. Seleção de leveduras produtoras de proteinases extracelulares. 1997. Dissertação (Mestrado em Microbiologia), Universidade Federal de Minas Gerais, Belo Horizonte. 71 pp. 
Braga, A. A., Morais, P. B.; Linardi, V. R. 1998. Screening of yeasts from brazilian amazon rain forest for extracellular proteinases production. Systematic and Applied Microbiology, (21): 353359.

Brock, T. D.; Madigan M. T.; Martinko, J. M.; Parker, J. Biology of Microorganisms. 1994. $7^{\text {th }}$. Prentice-Hall International, Inc., New York. 909pp.

Brumano, M. H. N., Coelho, J. L. C.; Araújo, E. F.; Silva, D. O. 1993. Production of pectin lyase by Penicillium griseoroseum as a function of the inoculum and culture conditions. Microbiol. Biotechnol., (9): 225-228.

Callegari-Jacques. 2003. Bioestatística: princípios e aplicaçôes. Artmed, Porto Alegre, 256pp.

Chaloupka, J. 1985. Temperature as a factor regulating the synthesis of microbial enzymes. Microbio. Sci., (2): 86-90.

Chantawannakul, P.; Oncharoen, A.; Klanbut, K.; Chukeatirote, E.; Lumyong, S. 2002. Characterization of proteases of Bacillus subtilis strain 38 isolated from traditionally fermented soybean in Northem Thailand. Science Asia, (28): 241- 245.

Danesi, E. D.G.; Wosiacki, G. 1998. Otimização da produção de nata (celulose bacteriana) por fermentação em superfície. Ciênc. Tecnol. Aliment. 18 (1): 131-139.

Deacon, J. W. 1997. Modern micology:: Blackwell Science, OxonNY. 303pp.

Dosoretz, C. G.; Chen, H. C.; Grethlein, H. E. 1990. Effect of Enviromental Conditions on Extracellular Protease Activity in Lignolytic Cultures of Phanerochaete chrysosporium. Applied and Environmental Microbiology, 56 (2): 395-400.

Fisher, F.; Cook, N. H. 1998. Fundamentals of Diagnostic Mycology. WB Saunders Co., Totowa-NJ. 352 pp.

Frankena, J.; Koningstein, G. M. ; van Verseveld, H. W.; Stouthamer, A. H. 1986. Effect of different limitations in chemostat cultures on growth and production of exocellular protease by Bacillus licheniformis. Appl. Microbiol. Biotechnol., (24): 106-112.

Freire, D. M. G. Seleção de microorganismos lipolíticos e estudo da produção de lipase por Penicillium restrictum. 1996. Tese (Doutorado em Bioquímica), Universidade Federal do Rio de Janeiro, Rio de Janeiro. 174pp.

Fungaro, M. H. P.; Fungaro, M. H. P.; Souza JR, C.L.; PizziraniKleiner, A. A.; Azevedo, J. A. 1994. Recurrent mutation selection to improve rennet production in Candida tsukubaensis. Revista Brasileira de Genética, (17): 377-382.

Garcia-Garibay, M.; Gomes-Ruiz, L.; Bárzana, E. 1987. Studies on the simultaneous production of a single cell protein and polygalacturonase from Kluyveromyces fragilis. Biotechnology Letters, (9): 6411-416.

Godfrey, T.; West, S. 1996. Industrial enzymology, $2^{\text {nd }}$ ed. Macmillan Publishers Inc, New York, N.Y. 73pp.

Griffin, D. H. 1994. Fungal physiology. 2nd. ed. Wiley-Liss, NY. 458pp.

Kanekar, P. P.; Nilegoankar, S. S.; Sarnaik, A. S.; Kellar, A. S. 2002. Optimization of protease activity of alkaliphilic bacteria isolated from an alkaline lake in India. Bioresource Technology, (85): 8793.
Kirsop, B. E.; Kurtzman, C. P. 1988. Yeast. Cambridge University Press, Cambridge. 233 pp.

Kreger-Van Rij, N .I. W. 1984. The yeast: a taxonomic study. 3th ed. Elsevier Sci. Public, Amesterdam. 1503 pp.

Kudrya, V.; A.; Simonenko, J. A. 1994. Alkaline serine proteinase and lection isolation from cultura of Bacillus subtilis. Applied microbial Biotechnology. Abstrat-EMBASE, 233-236 p.

Leighton, T .J.; Doi, R. H.; Warren, R.A. J.; Kelln, R. A. 1973. The relationship of serine protease activity to RNA polymerase modification and sporulation in Bacillus subtilis. J. Mol. Biol., (76): 103-122.

Lodder, J. 1984. The yeast-Taxonomic study. 2nd. ed. North-Holland Publishing Company, Amsterdarn. 1002 pp.

Macdonald, F.; Odds, F. C. 1980. Inducible proteinase of Candida albicans in diagnostic serology and in the pathogenesis of systemic candidiasis. Journal of Medical Microbiology. (13): 423 - 435.

Mendes-Giannini, M. J. S.;Ricci, R. A.; Hanna, S.A.; Salina, M. A. 1997. Fatores envolvidos na patogênese fúngica. Revista Ciências Farmacêuticas, 18 (2): 207-229.

Midgley, G.; Hay, J. R.; Clayton, Y.M. 1998. Diagnóstico em cores micologia médica. Editora Manole, São Paulo-SP. 155pp.

Nampoothiri, K. M.; Pandey, A. 1995. Glutamic acid fermentation Brevebacterium DSM 20411. J. Food Sci. Technol., 32 (5): 406408.

Nunes, T. A. 1998. Espécies de Cladosporium de interesse médico isoladas de solo e de vegetais de áreas de lazer da cidade do Recife, PE, Brasil. Dissertação (Mestrado). Recife-PE. 69pp.

Ogrydziak, D. M. 1993. Yeast extracellular proteases. Crit. Rev. Biotechnol., (13): 1-55.

Papagianni, M.; Moo-Young, M. 2002. Protease secretion in glucomylase producer Aspergillus niger cultures: fungal morphology and inoculum effects. Process Biochemistry, (37): $1271-1278$.

Petinate, S. D. G.; Martins, R. M.; Coelho, R. R. R.; Meirelles, M. N. L.; Branquinha, M. H.; Vermelho, A. B. 1999. Influence of growth medium in proteinase and pigment production by Streptomyces cyaneus. Mem. Inst. Oswaldo Cruz, 94 (2): 173-177.

Porto, A. L. F.; Campos-Takaki, G. M.; Lima Filho, J. L. 1996. Effects of culture conditions on protease prodution by Streptomyces clavuligerus growing on the soy bean flour medium. Applied Biochemistry and Biotechnology. (60): 115-122.

Price, M. F.; Wilkinson, I. D.; Gentry, L. O. 1982. Plate method for detection of phospholipase activity in Candida albicans. Sabouraudia. (20): 7-14.

Rodrigues, A. N.; Sant'Anna, E. S. 2001. Efeito do cloreto de sódio na produção de proteínas (Saccharomyces cervisiae) em fermentação semi-sólida. Ciênc. Tecnol. Aliment., 21 (1): 63-66.

Shimizu, K.; Kondoh, Y.; Nojiro, K. 1987. Proteinase production and pathogenicity of Candida albicans. Microbiol. Immunol., 31 (11): 1045- 1060 .

Soares, V. F.; Ferreira, V. S.; Bon, E. P. S. 1999. Produção de Proteases de Bacillus subtilis usando óleo de soja como fonte de carbono. In: $4^{\circ}$ Seminário Brasileiro de Tecnologia Enzimática. Resumos. Universidade Federal do Rio de Janeiro, Rio de Janeiro. 98pp. 


\section{ACTA
AMAZONICA}

SELEÇÃO DE LEVEDURAS DA REGIÃO AMAZÔNICA

PARA PRODUÇÃO DE PROTEASE EXTRACELULAR

Stanbury, F. P.; Whitaker, A. 1984. Principles of fermentation technology. 1st. ed. Pergamon Press, Oxford. 255pp.

Teixeira, M. F. S.; Fernandes, O. C. C.; Herrera, A. M.; Durán, N. 1996. Determinação qualitativa de proteases: método de cupplate modificado. Rev. UFAM. Série: Ciências da Saúde, 4/5 (1/ 2): 39-45.

Teixeira, M. F. S. 1997. Otimização da produção de enzimas pectinoliticas por Aspergillus japonicum 586. Tese (Doutorado em Biotecnologia), Universidade Federal de Pemambuco, Recife. 152pp.

Togni, G. D.; Sanglard, R.; Falchetto, R.; Monod, M. 1991. Isolation and nucleotide sequence of the extracellular acid protease gene (ACP) from yeast Candida tropicalis. FEBS Lett., (286): 181185.

Tornai-Lehoczki, J. ; Péter, G. ; Dlauchy , D. 2003. CHROMagar Candida medium as a pratical tool for the differentiation and presumptive identification of yeast species isolated from salads. Inter. J. of Food Microbiology, (86): 189-200.

Tucker, K. G.; Thomas, C. R. 1994. Inoculum effects on fungal morphology: shake flasks vs agitated bioreactors. Biotechn. Techn., (8): $153-156$.

Vermelho, A. B., Meirelles, M. N. L.; Lopes, A.; Petinate, S. D. G.; Chaia, A. A.; Branquinha, M. H. 1996. Detection of extracellular proteases from microorganisms on agar plates. Mem. Inst. Oswaldo Cruz, 91(6): 755-760.
Woolford, C. A.; Daniels, L. B.; Park, F. J.; Jones, E. W,; Van Arsdell, J. N.; Innis, M. A. 1989. The PEP4 gene encodes an aspartyl protease implicated in the post-translational regulation of Saccharomyces cerevisiae vacuolar hydrolases. Mol. Cell. Biol., (6): 2500- 2510.

Yamamoto, T.; Yamamoto, T.; Nohara, K.; Uchida, K.; Yamaguchi, H. 1992. Purification and characterization of secretory proteinase of Candida albicans. Microbiology and Immunology. 36 (6): $637-641$.

Yamashita, L. D.; Ilirata, D.; Machida, M.; Fukui, S. 1986. Cloning and expression in Saccharomyces cerevisiae of the secretable acid protease gene from Saccharomycopsis fibuligera. Agric. Biol. Chem., (50): 109- 113 .

Yang, F.; Lin, I. 1998. Production of acid protease using thin stillage from a rice-spirit distillery by Aspergillus niger. Enzyme and Microbial Technology, (23): 397- 402.

Yang, J.; Shih, I.; Tzeng, Y.; Wang, S. 2000. Production and purification of protease from a Bacillus subtilis that can deproteinize crustacean wastes. Enzyme and Microbial Technology, (26): 406- 413 .

Recebido em 23/04/2004

Aceito em 04/05/2006 